\title{
Multiomic Analyses of Dopaminergic Neurons Isolated from Human Substantia Nigra in Parkinson's Disease: A Descriptive and Exploratory Study
}

\author{
Affif Zaccaria ${ }^{1}$ (D) Paola Antinori ${ }^{1}$ - Virginie Licker ${ }^{1}$ - Enikö Kövari ${ }^{2}$. Johannes A. Lobrinus ${ }^{3}$. Pierre R. Burkhard ${ }^{1,4}$
}

Received: 18 February 2021 / Accepted: 2 September 2021 / Published online: 15 September 2021

(c) The Author(s) 2021

\begin{abstract}
Dopaminergic neurons (DA) of the substantia nigra pars compacta (SNpc) selectively and progressively degenerate in Parkinson's disease (PD). Until now, molecular analyses of DA in PD have been limited to genomic or transcriptomic approaches, whereas, to the best of our knowledge, no proteomic or combined multiomic study examining the protein profile of these neurons is currently available. In this exploratory study, we used laser capture microdissection to extract regions from DA in 10 human SNpc obtained at autopsy in PD patients and control subjects. Extracted RNA and proteins were identified by RNA sequencing and nanoliquid chromatography-mass spectrometry, respectively, and the differential expression between PD and control group was assessed. Qualitative analyses confirmed that the microdissection protocol preserves the integrity of our samples and offers access to specific molecular pathways. This multiomic analysis highlighted differential expression of 52 genes and 33 proteins, including molecules of interest already known to be dysregulated in PD, such as $L R P 2$, $P N M T, C X C R 4, M A O A$ and $C B L N 1$ genes, or the Aldehyde dehydrogenase 1 protein. On the other hand, despite the same samples were used for both analyses, correlation between RNA and protein expression was low, as exemplified by the CST3 gene encoding for the cystatin $\mathrm{C}$ protein. This is the first exploratory study analyzing both gene and protein expression of laser-dissected neuronal parts from SNpc in PD. Data are available via ProteomeXchange with identifier PXD024748 and via GEO with identifier GSE 169755.
\end{abstract}

Keywords Parkinson's disease - Human brain tissue - Dopaminergic neurons · Laser capture microdissection · Transcriptomics $\cdot$ Proteomics

\section{Abbreviations \\ $\mathrm{SN} p c \quad$ Substantia nigra pars compacta \\ PD Parkinson's disease}

Affif Zaccaria and Paola Antinori are the co-first authors.
DA Dopaminergic neurons

LCM Laser capture microdissection

LFQ Label-free quantification

RIN RNA integrity number

GFP Gas-phase fractions

All authors of the manuscript have read and agreed to its content.

\section{Affif Zaccaria \\ Affif.zaccaria@unige.ch \\ Paola Antinori \\ Paola.antinori@unige.ch \\ Virginie Licker \\ Virginie.licker@unige.ch \\ Enikö Kövari \\ eniko.kovari@hcuge.ch}

Johannes A. Lobrinus

johannes.a.lobrinus@hcuge.ch

Pierre R. Burkhard

pierre.burkhard@hcuge.ch
1 Neuroproteomics Group, University Medical Center, Faculty of Medicine, Geneva University, Geneva, Switzerland

2 Department of Psychiatry, Geneva University Hospitals, Geneva, Switzerland

3 Department of Pathology, Geneva University Hospitals, Geneva, Switzerland

4 Department of Neurology, Geneva University Hospitals, Geneva, Switzerland 
LC Liquid chromatography

MS Mass spectrometry

\section{Introduction}

Parkinson's disease (PD) is the most common neurodegenerative movement disorder, currently affecting about seven million people worldwide (Kalia and Lang 2015). Despite decades of extensive basic and translational research, PD remains an incurable condition, and the cause and mechanisms of the degeneration of dopaminergic neurons (DA) in the substantia nigra pars compacta ( $\mathrm{SN} p c$ ) remain to be fully elucidated. Since the emergence of high-throughput omics technologies some twenty years ago, several groups (Redensek et al. 2018), including ours, have been able to study the molecular profile of post-mortem SNpc samples with the purpose of identifying differential and specific molecular expression changes in PD compared to controls. Although these works allowed the in-depth molecular exploration of SNpc and the identification of altered signaling pathways such as inflammation (McGeer and McGeer 2004), oxidative stress (Jenner 2003), proteasome (McNaught et al. 2001), mitochondrial or cell iron pathways (Berg et al. 2001), there is still no consensus about the molecular cascade at the basis of nigral DA degeneration in PD brains. Failure to dissect these approaches more specifically could be mainly related to the nature of samples under study, i.e., the whole $\mathrm{SN} p c$ specimens that were compared between control and PD groups. Indeed, the molecular analysis of whole PD SNpc mainly involved glial cells owing to the PD-related dramatically reduced component of DA neurons, whereas the molecular analysis of control SNpc integrated a higher proportion of DA neurons, resulting in unbalanced and biased comparisons.

Thus, a first step toward a better understanding of nigral degeneration would require specific molecular analyses of DA neuronal regions from PD SNpc. In 2009, Simunovic et al. (2009) used laser capture microdissection (LCM) and RNA microarrays to analyze gene expression of dissected DA neurons from SN $p c$ in PD samples. They identified a dysregulation of several known molecular regulatory pathways involved in PD pathogenesis such as oxidative stress-induced cell responses or dysfunction of the mitochondrial and ubiquitin-proteasome systems. However, this study, which focused on mRNA data only, revealed transcriptional activation of genes but did not inform about the protein expression level and function.

In 2016, the first proteomic study that focused on DA neurons was published by Plum et al. (2016). By combining LCM with nanoliquid chromatography mass spectrometry (nano-LC-MS/MS), they identify 1068 distinct proteins in DA neurons from healthy $\mathrm{SN} p c$ samples, but did not include PD samples in the study.
Therefore, to the best of our knowledge, there is still no published work applying quantitative proteomics to DA neuronal regions from $\mathrm{SN} p c$ samples in $\mathrm{PD}$, or simultaneously applying both transcriptomic and proteomic workflows to the same samples in PD.

Over the last decade, the progressive improvements of LCM technology (Espina et al. 2007) in automation, velocity, and precision offer the opportunity to dissect frozen DA neuronal regions in conditions that are more suitable for relevant molecular analyses. The increased sensitivity of mass spectrometers and RNA sequencers enables comparative and quantitative multiomic approaches using low to very low amounts of biological material.

In this exploratory study, we used LCM to dissect DA neuronal regions from control and PD post-mortem SNpc specimens. In the first part, we used both qualitative transcriptomic and proteomic approaches, to confirm the integrity and validity of our samples, and the LCM-provided access to the specific protein content of DA neurons. This important quality control step led to the second part of this study, where a quantitative comparison of protein and gene expression by label-free approach and RNA sequencing (RNAseq), respectively, was performed in DA neuronal regions from control and PD samples. Importantly, the same specimens were used for both analyses. RNAseq analysis revealed 52 differentially expressed genes, and labelfree proteomics highlighted 33 differentially expressed proteins in PD samples compared to matched controls. Transcriptomics and proteomics results were compared to identify the mRNA-protein couples for which the expression changes followed the same direction. This work is the first attempt to propose a multiomic analysis of DA neurons in the PD brain.

\section{Methods}

\section{Human Brain Tissues}

Ten frozen human midbrains, five from age-matched control patients, and five from PD patients were collected during 2 years by the Department of Clinical Pathology and Psychiatry of the Geneva University Hospitals under a procedure approved by the Geneva Ethical Committee (Table 1) and registered under the number CER 05-066 in accordance with the relevant guidelines and regulations. Written informed consent for brain autopsy and use for research was obtained from close family relatives. PD diagnosis was confirmed neuropathologically and controls, with no previous history of neurological or psychiatric disorders, were confirmed to be free of nigral abnormalities. Samples were cryopreserved at $-80{ }^{\circ} \mathrm{C}$ until further analysis. 
Table 1 Summary for brain samples

\begin{tabular}{lllllll}
\hline Case ID & Primary diagnosis & Gender & Age (years) & PMI (h) & Proteomics & $\begin{array}{c}\text { Tran- } \\
\text { scrip- } \\
\text { tomics }\end{array}$ \\
\hline C1 & Control & M & 77 & 34 & $\mathbf{x}$ & \\
C2 & Control & M & 85 & 31 & $\mathbf{x}$ & \\
C3 & Control & F & 87 & 34 & $\mathbf{x}$ & $\mathbf{x}$ \\
C4 & Control & M & 70 & 35 & $\mathbf{x}$ & $\mathbf{x}$ \\
C5 & Control & M & 64 & 19 & $\mathbf{x}$ & $\mathbf{x}$ \\
PD1 & Parkinson's disease & M & 79 & 17 & $\mathbf{x}$ & \\
PD2 & Parkinson's disease & M & 84 & 38 & $\mathbf{x}$ & $\mathbf{x}$ \\
PD3 & Parkinson's disease & F & 79 & 33 & $\mathbf{x}$ & $\mathbf{x}$ \\
PD4 & Parkinson's disease & M & 73 & 25 & $\mathbf{x}$ & $\mathbf{x}$ \\
PD5 & Parkinson's disease & M & 73 & 25 & $\mathbf{x}$ & \\
\hline
\end{tabular}

$P M I$ post-mortem interval

\section{Proteomic Analysis}

\section{Laser Capture Microdissection}

$12 \mu \mathrm{m}$ tissue slices from each SNpc were cut at $-18{ }^{\circ} \mathrm{C}$ (Leica CM3050, Biosystems Switzerland AG, Muttenz, $\mathrm{CH}$ ), mounted on $2 \mu \mathrm{m}$ PEN membrane slides (Leica Biosystems Switzerland AG, Muttenz, Switzerland), fixed and dehydrated in ethanol. Collection of control and patient DA neurons was alternated to avoid a time-related bias.

DA neuronal regions were visually identified by their brown neuromelanin pigment under bright field microscopy on a Leica LCM6000 instrument (Leica Microsystems GmbH, Wetzlar, Germany). Approximately 2050 regions of DA neurons were accurately delimited at $\times 200$ magnification to reduce contamination by surrounding tissue, microdissected, and catapulted into the vial cap in $8 \mu \mathrm{l}$ of RapiGest $^{\mathrm{TM}} 0.1 \%$ (Waters, GmbH, Milford, MA, USA) in TEAB 0.1 M (Sigma-Aldrich Inc., St. Louis, MO, USA). The vial was vortexed upside-down, centrifuged to recover the sample at the bottom, and sonicated with a VialTweeter UIS250v (Hielscher Ultrasonics GmbH, Teltow, Germany) to foster lysis and DA-neuron detachment from the PEN membrane ( $70 \%$ amplitude, $0.5 \mathrm{~s}$ cycle, 20 bursts, 5 times, on ice between each cycle). Samples were stored at $-80^{\circ} \mathrm{C}$.

\section{Proteomic Analysis with Mass Spectrometry}

Microdissected DA neuronal regions were thawed simultaneously, the volume was adjusted to $100 \mu \mathrm{l}$ with lysis buffer (RapiGest ${ }^{\mathrm{TM}} 0.1 \%$ Waters, Corporation, Milford, MA; TEAB 0.1 M; Sigma-Aldrich, St. Louis, MO), and protein concentration was estimated with a NanoDrop ${ }^{\mathrm{TM}}$ 2000 spectrophotometer (Waltham, Massachusetts, USA). For trypsin digestion, the proteins were treated with TCEP $1 \mathrm{mM}$ (Sigma-Aldrich, St. Louis, MO) $\left(1 \mathrm{~h}\right.$ at $60{ }^{\circ} \mathrm{C}$;
Sigma-Aldrich, Saint-Louis, US-MO) and iodoacetamide $4 \mathrm{mM}$ (30 min at room temperature in the dark, shaking at $250 \mathrm{rpm}$, Sigma-Aldrich, St. Louis, MO), and trypsin (porcine, Promega Corporation, Madison, WI) was added to samples in a 1:25 ratio overnight. The reaction was stopped with $10 \%$ FA. RapiGest ${ }^{\mathrm{TM}}$ was removed by acid precipitation after incubation at $37{ }^{\circ} \mathrm{C}$ for $40 \mathrm{~min}$ and centrifugation at 13,000 rpm for $20 \mathrm{~min}$. The supernatant with the peptides was cleaned with a $\mathrm{C}_{18}$ microspin column (Harvard Apparatus, Holliston, MA) according to the manufacturer instructions, dried under speed-vacuum, and stored at $-80^{\circ} \mathrm{C}$.

MS analysis was performed according to the protocol of the Proteomics Core Facility of the University of Geneva (https://www.unige.ch/medecine/proteomique/), as previously described (Dor et al. 2019).

Peptide digests were solubilized in 5\% acetonitrile and analyzed by electrospray ionization on a linear trap quadrupole (LTQ) Orbitrap velos Pro (Thermo Scientific, San Jose, CA, USA) equipped with a NanoAcquity system (Waters, Milford, MA, USA). Peptides were trapped on a home-made $5 \mu \mathrm{m} 200 \AA$ A Magic $\mathrm{C}_{18}$ AQ (Michrom) $0.1 \times 20 \mathrm{~mm}$ pre-column and separated on a commercial $0.075 \times 150 \mathrm{~mm}$ Nikkyo (Nikkyo Technology, Tokyo, JPN) analytical nanocolumn $\left(\mathrm{C}_{18}, 5 \mu \mathrm{m}, 100 \AA\right.$ ). The analytical separation was run for $54 \mathrm{~min}$ (flow rate $200 \mathrm{nl} / \mathrm{min}$ ) using a gradient as follows: $0-1 \mathrm{~min} 95 \% \mathrm{~A}(0.1 \% \mathrm{FA})$ and $5 \%(99.9 \%$ acetonitrile, $0.1 \%$ formic acid) then to $65 \% \mathrm{~A}$ and $35 \% \mathrm{~B}$ for $55 \mathrm{~min}$, and $20 \%$ $A$ and $80 \%$ B at 65 min. For MS survey scans, the orbitrap (OT) resolution was set to 60,000 and the ion population was set to $5 \times 105$ with an $\mathrm{m} / \mathrm{z}$ window from 400 to 2000 .

Three gas-phase fractions (GPF) for data-dependent MS/MS selection were defined in the following $\mathrm{m} / \mathrm{z}$ ranges: 400-598, 593-746, and 741-2000 Th (Scherl et al. 2008).

Five precursor ions were selected for collision-induced dissociation (CID) in the LTQ. The ion population was set to $1 \times 104$ (isolation width of $2 \mathrm{~m} / z$ ), while for MS/MS 
detection in the OT, it was set to $1 \times 105$ with an isolation width of $2 \mathrm{~m} / z$ units. The normalized collision energies were set to $35 \%$ for CID.

\section{Data Analysis for Proteomics}

MaxQuant (version 1.5.8.3) was used to process Thermo raw files. For protein identification, data were searched against the UniProtKB/Swiss-Prot human database (release 2018_05, with 26,336 protein entries). N-terminal protein acetylation and methionine oxidation were set as variable modifications and cysteine carbamido methylation as fixed. The default parameters were used for the instrument choice. Only one missed cleavage was allowed and search for second peptide matches and match between runs were activated. Peptides and protein FDR was set to 0.01 . For protein quantification, label-free quantification (LFQ) was chosen with a min. ratio count of 1 and unique + razor peptides were used. The other parameters were left as defaults.

Data analysis was performed using Perseus software. Common contaminants were filtered out and LFQ protein intensities were $\log _{2}$ transformed. At least $70 \%$ of protein intensities were required overall before imputing the missing values from a normal distribution. LFQ intensities were averaged across technical replicates before performing a two-sample $t$-test. Proteins with a $p$-value $<0.05$ and a fold change $>1.5$ were considered differentially expressed between patients and controls.

The MS proteomics data have been deposited to the ProteomeXchange Consortium via the PRIDE partner repository (Perez-Riverol et al. 2019) with a dataset identifier PXD024748. The description of each submitted file is detailed in Supplementary Information SI-4.

\section{Gene Expression Analysis}

\section{LCM for Gene Expression Analysis}

For gene expression analysis, we used three PD samples and three controls, for which $\mathrm{SN} p c$ was still available after proteomic sample preparation.

$12 \mu \mathrm{m}$ tissue slices from each substantia nigra were cut at $-18{ }^{\circ} \mathrm{C}$ and processed as described in the proteomic section. Approximately 70 regions of DA neurons were dissected in duplicates for each of the six different samples and collected by gravity in distinct vials. The 12 resulting groups of DA neuronal regions were quickly frozen on dry ice and stored at $-80{ }^{\circ} \mathrm{C}$.

\section{RNA Extraction for Quality Control}

Tissue depleted of DA neuronal regions after LCM was also collected from the slides in $100 \mu \mathrm{l}$ of lysis/denaturing buffer from the RNAqueous micro kit (Life Technologies, Zug, Switzerland). RNAs were extracted following the manufacturer protocol, quantified with a $\mathrm{Qbit}^{\mathrm{TM}}$ fluorometer (Thermo Fisher, Waltham, MA, US), and analyzed with an Agilent 2100 Bioanalyser (Agilent Technologies, Palo Alto, CA) to check the RNA profile and obtain the RNA integrity number (RIN).

\section{RNAseq Library Preparation and Sequencing of NM-Granules}

The SMARTerTM Ultra Low RNA kit from Clontech was used for the reverse transcription and cDNA amplification according to the protocol described by Vono et al. (2019), starting with 70 cells as input. Samples were defrozen simultaneously and solubilized in $10 \mu \mathrm{l}$ of lysis buffer. After reverse transcription and amplification, $200 \mathrm{pg}$ of cDNA were used for library preparation using the Nextera XT kit from Illumina. Library quality and molarity were assessed with the Qbit and Tapestation using a DNA High sensitivity chip (Agilent Technologies). Pools of 12 libraries were diluted at $2 \mathrm{nM}$ for clustering on a Single-read Illumina Flow cell. Reads of 50 bases were generated using the TruSeq SBS chemistry on an Illumina HiSeq 4000 sequencer at the iGE3 Genomics Platform of the University of Geneva (https://ige3.genomics.unige.ch).

\section{RNAseq Data Analysis}

Sequencing quality control was performed with FastQC (v.0.11.5). Sequencing data were mapped to the UCSC human hg38 reference genome using STAR aligner (v.2.5.3a). The transcriptome metrics were evaluated with the Picard tools (v.1.141) and informed the decision to exclude two samples due to a low number of reads assigned to a gene.

The differential expression analysis PD/controls was carried out with the statistical Bioconductor package edgeR (v.3.14.0). The gene counts were normalized according to the library size. The genes having a count above 1 count per million reads (cpm) in at least two samples were carried forward for the analysis. The list of 26,485 genes was reduced to 22,561 after filtering out the poorly or not expressed genes. The differentially expressed gene tests were done with a GLM (general linear mode) with a negative binomial distribution. $p$-values were corrected for multiple testing error with a 5\% FDR using the Benjamini-Hochberg procedure to retain only the significant genes.

In order to check whether the protein product of the differentially expressed genes has been already detected by MS, we generated a list of brain proteins with Nextprot (Gaudet et al. 2017) using the Advanced search (SPARQL) tool and 
querying for human proteins identified in the brain by MS with two distinct peptides seven or more aminoacids long.

Gene expression data have been deposited on Gene Expression Omnibus (GEO) under the identifier GSE 169755.

\section{Results}

\section{Integrity and Quality of Samples by Transcriptomics}

Before proceeding to the quantitative comparisons between PD and control samples, we controlled that our sample preparation protocol preserved extracted molecules in sufficient quality for omics analyses. As RNAs are known to be more vulnerable entities than proteins, we used transcriptomic approaches to analyze RNA quality of our samples, by different ways, at different steps of the workflow.

To this purpose, tissue slices from $\mathrm{SN} p c$ of controls and PD patients (Table 1) were mounted on slides for LCM of DA neuronal regions (Fig. 1). About 70 zones of DA neurons, per sample, were microdissected in duplicates and collected in distinct vials. For each sample, after dissection, we collected on slide the remaining tissue into lysis buffer, extracted RNAs, and determined their quality through observation of their electrophoretic profiles and the RIN measurement (Fig. 2). The electrophoretic profiles revealed an average RIN of 6.0 and 6.6 for PD and control samples, respectively. And although it showed decreased $18 \mathrm{~S}$ and $28 \mathrm{~S}$ peak intensity, peaks were clearly visible and positioned at the right nucleotide size (Fig. 2; Supplemental Table 1). In this context, we considered RNA quality as good enough to proceed to cDNA amplification with the SMARTer ${ }^{\mathrm{TM}}$ Ultra Low RNA kit. Starting with an average of 70 regions of DA neurons per sample, the cDNA concentration obtained after amplification was homogeneous across all samples with an average cDNA concentration of $0.15 \pm 0.01 \mathrm{ng} / \mu \mathrm{l}$ in PD samples and $0.16 \pm 0.04 \mathrm{ng} / \mu \mathrm{l}$ in control samples and a global average cDNA concentration of $0.15 \pm 0.03 \mathrm{ng} / \mu \mathrm{l}$ (Supplemental Table 2). 200 pg of cDNA were used to generate one library for each individual sample. The average fragment size was $300 \mathrm{bp}$ and the fragments distribution

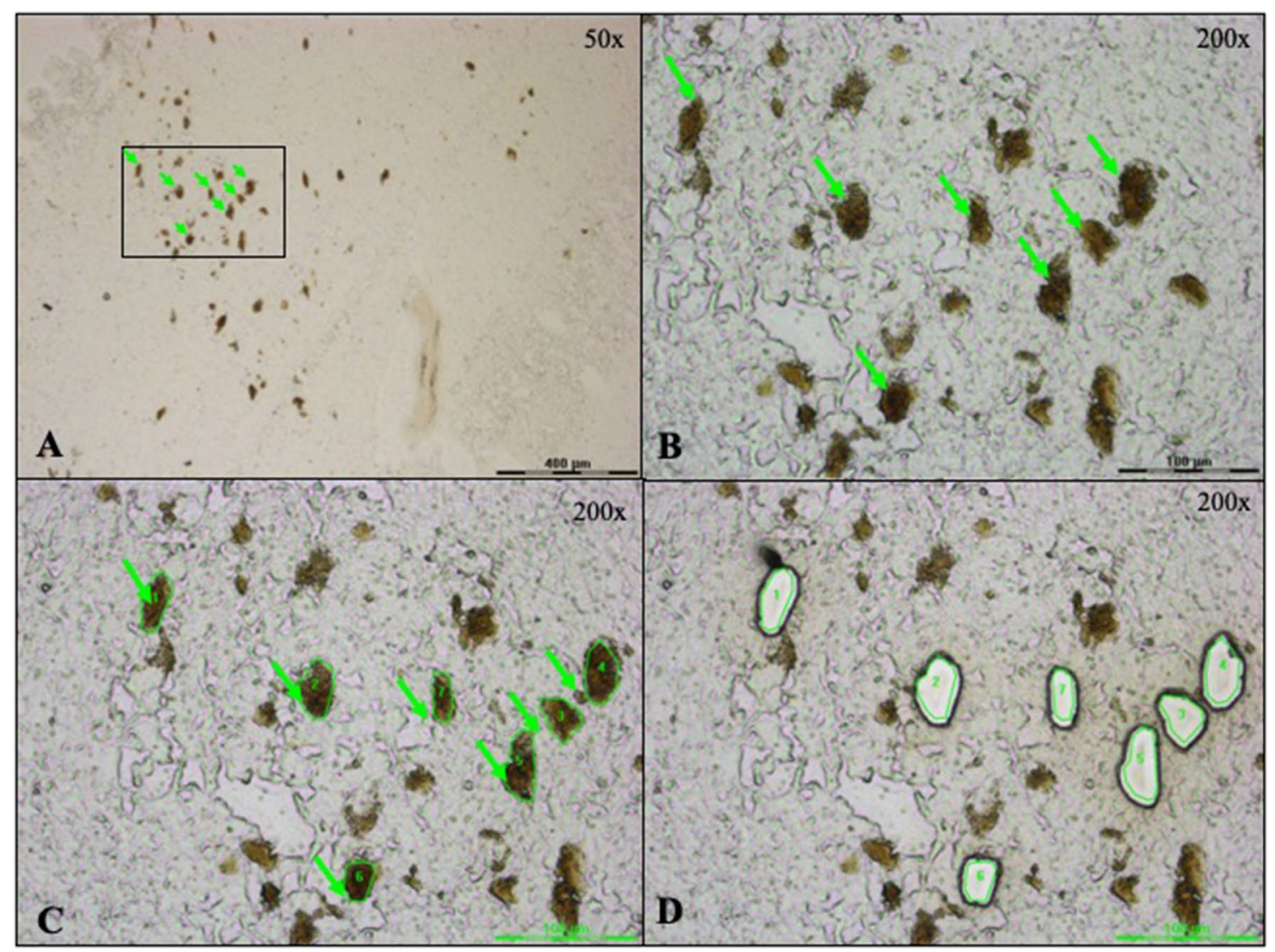

Fig. 1 LCM capture of DA neurons from a section of substantia nigra tissue mounted on a PEN membrane slide. A DA neurons (pointed by the green arrows) can be visually identified by their brown pigment ( $\times 50$ magnification). The black rectangle highlights the region depicted in figures $(\mathbf{B}-\mathbf{D})$ at $\times 200$ magnification. $\mathbf{C}$ The green lines define the DA neurons to guide the laser beam. D The shapes appear empty after cutting and collecting the granules in the tube cap situated under the slide 


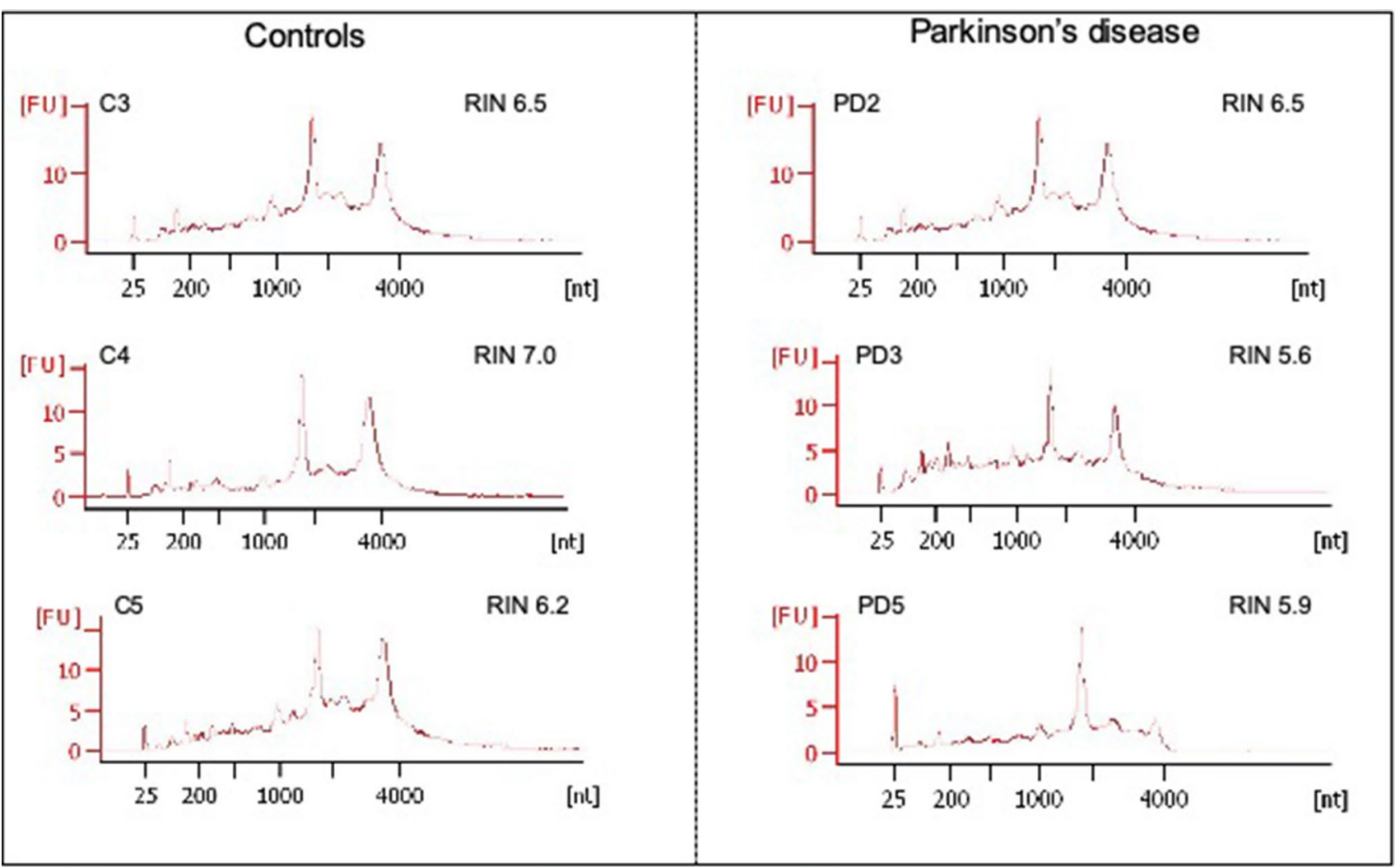

Fig. 2 Quality control of RNA extracted from DA neurons in PD and control samples. The electrophoretic profiles and the resulting RNA integrity number (RIN) were obtained to confirm integrity of all samples and were compared between control and PD samples

was homogeneous across all samples, with no significant difference between control and PD groups (Supplemental Table 2). Altogether, these results validated the sufficient quality and homogeneity of our samples, two important aspects before initiating quantitative comparisons between control and PD groups.

\section{Assessment of LCM Specificity by Proteomics}

In order to validate the capacity of our protocol to specifically highlight the molecular content of DA neuronal regions, we performed a proteomic analysis of this region collected from five control samples and five PD samples (Table 1). To obtain a sufficient amount of protein extract to perform triplicate injections for three $\mathrm{GPFs}^{11}$ for datadependent MS/MS selection, we dissected at $\times 200$ magnification an average of 2050 regions of DA neurons per sample (Supplemental Information 1), covering an average area of $750,000 \mu \mathrm{m}^{2}$. To obtain this quantity of biological material, an average of 16 and 37 tissue sections were LCM-processed for control and PD samples, respectively.

The total amount of proteins extracted from these neurons ranged from 18 to $24 \mu \mathrm{g}$. $6 \mu \mathrm{g}$ proteins of each sample were trypsin digested and injected in triplicates for three GPF runs with nano-LC-MS/MS. Data analysis with MaxQuant allowed the identification of 727 to 843 distinct proteins (Fig. 3). The comparison of these 10 protein-lists highlighted a total of 1034 distinct proteins, identified by at least two proteotypic peptides (SI-1).

To confirm the quality of our DA-neuron enrichment using LCM approach, we compared our protein list with the list published by Plum et al. (2016). These authors identified 1068 distinct proteins, a figure very similar to our study. Interestingly, there was a $74 \%$ overlap between the two lists. In fact, 760 of the 1034 proteins were identified in both studies. Then, to demonstrate that dissection of DA neuronal region, a subcompartment of $\mathrm{SN} p c$, gave access to a specific subproteome, we compared our 1034 proteins with the most exhaustive proteome of whole SNpc, published by our group in 2014 (Licker et al. 2014), with a list of 1795 different species (Fig. 4 and SI-3). On the one hand, among the 1034 proteins identified into dissected DA neurons, 862 species were also identified into the whole $\mathrm{SN} p c$. On the other hand, 170 proteins were only present into the DAneuron compartment (SI-3). In fact, while these 170 proteins were identified in at least $80 \%$ of DA-neuron samples, they were never identified into the whole $\mathrm{SN} p c$ samples. Interestingly, the comparison of the whole $\mathrm{SN} p c$ with Plum 


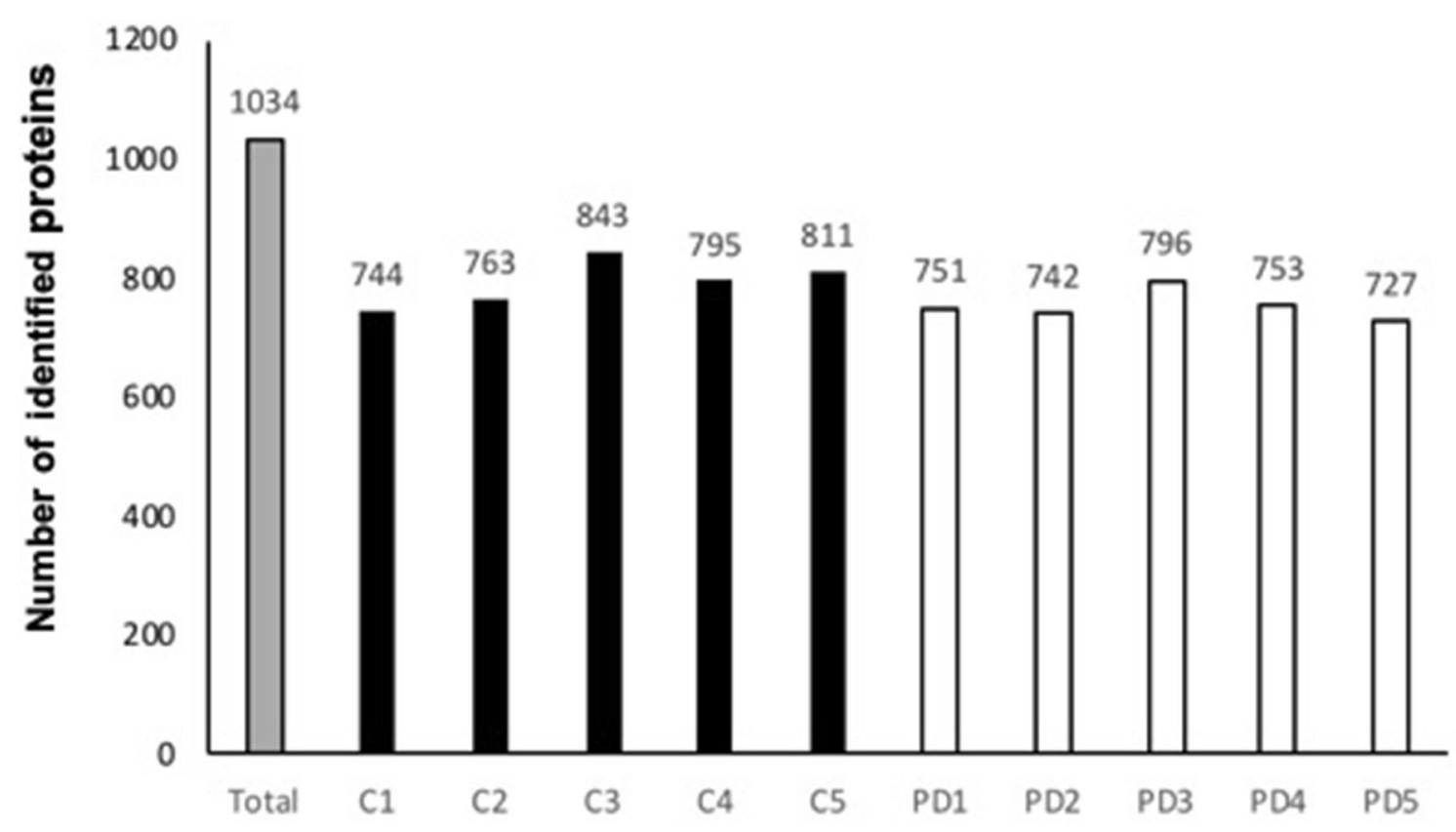

Fig. 3 Number of proteins identified in DA neurons of post-mortem SNpc by nano-LC-MS/MS: across all analyzed samples (Total), in control samples (C1 to C5) and Parkinson's disease samples (PD1 to PD5)

Fig. 4 Qualitative comparison of proteins identified from DA neurons with whole $\mathrm{SN} p c$. Venn diagram representing both common and specific proteins identified in whole $\mathrm{SN} p c$ and DA neurons
Whole SNpc from Licker et al.

1795 different proteins

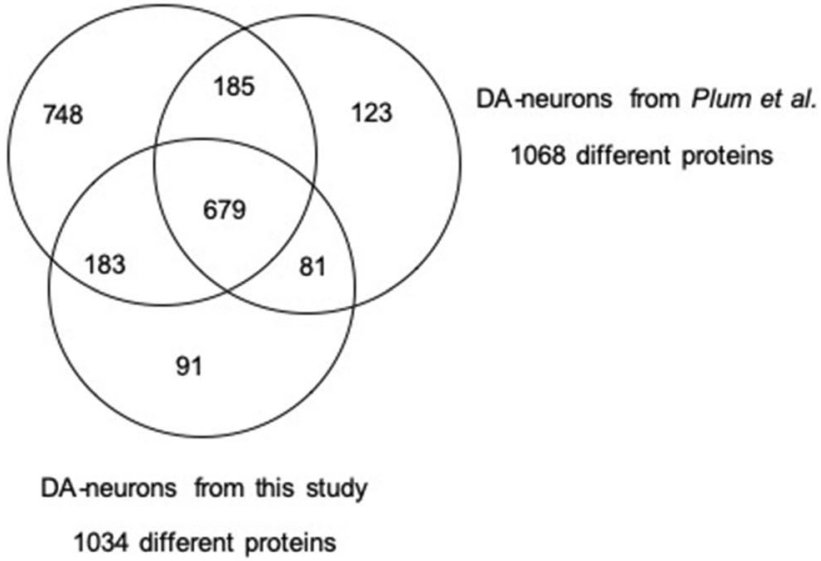

quantitative multiomic approaches to identify PD-related specific events in DA neurons.

\section{Differential Expression Between Control and PD Samples}

To proceed to comparative analyses between PD and control samples through multiomic workflows, we first compared the mRNA abundance of 17,002 protein-coding genes between $\mathrm{PD}$ and control in DA neuronal regions (SI-2). A total of 52 genes $(0.3 \%)$ showed significantly different gene expression at FDR $p$ values $<0.05$. In PD samples, RNA expression was increased for 40 genes and decreased for 12 genes (Table 2). Among these 52 differentially expressed genes, at least 10 subproteome. These results strengthened the interest for 
Table 2 Differentially expressed genes between PD and control samples

\begin{tabular}{|c|c|c|c|c|c|c|}
\hline & Gene Name & Description & $\begin{array}{l}\text { Fold } \\
\text { Change } \\
\text { PD/CTR }\end{array}$ & $\begin{array}{l}\mathrm{p}- \\
\text { value }\end{array}$ & $\begin{array}{l}\text { Identification of } \\
\text { the } \\
\text { corresponding } \\
\text { protein in our } \\
\text { study }\end{array}$ & $\begin{array}{l}\text { Identification of } \\
\text { the } \\
\text { corresponding } \\
\text { protein in any } \\
\text { brain MS-studies }\end{array}$ \\
\hline 1 & EHF & ETS homologous factor (hEHF) & 193,4 & $3,2 \mathrm{E}-05$ & NO & NO \\
\hline 2 & MT1H* & Metallothionein-1H & 98,3 & $3,3 \mathrm{E}-06$ & NO & NO \\
\hline 3 & CHIT1 & Chitotriosidase-1 & 79,1 & $1,4 \mathrm{E}-04$ & NO & YES \\
\hline 4 & KCNJ8 & ATP-sensitive inward rectifier potassium channel 8 & 40,9 & $6,5 \mathrm{E}-05$ & NO & NO \\
\hline 5 & CXCR4* & C-X-C chemokine receptor type 4 & 16,0 & $1,3 \mathrm{E}-04$ & NO & NO \\
\hline 6 & PNMT* & Phenylethanolamine $\mathrm{N}$-methyltransferase & 10,0 & $1,1 \mathrm{E}-04$ & NO & NO \\
\hline 7 & BTG3* & Protein BANP & 8,3 & $2,5 \mathrm{E}-05$ & NO & NO \\
\hline 8 & STC1 & Stanniocalcin-1 & 7,6 & $7,4 \mathrm{E}-07$ & NO & NO \\
\hline 9 & SLC18A1 & Vesicular amine transporter 1 & 7,3 & $1,8 \mathrm{E}-05$ & NO & NO \\
\hline 10 & LRP2* & Low-density lipoprotein receptor-related protein 2 & 7,3 & $4,8 \mathrm{E}-05$ & NO & YES \\
\hline 11 & NRP2 & Neuropilin-2 & 7,2 & $1,2 \mathrm{E}-04$ & NO & YES \\
\hline 12 & TGFBR3 & Transforming growth factor beta receptor type 3 & 7,2 & $1,2 \mathrm{E}-04$ & NO & YES \\
\hline 13 & EFEMP1 & EGF-containing fibulin-like extracellular matrix protein 1 & 7,0 & $2,2 \mathrm{E}-06$ & NO & YES \\
\hline 14 & ANTXR2 & Anthrax toxin receptor 2 & 5,9 & $1,3 \mathrm{E}-04$ & NO & NO \\
\hline 15 & JAM2 & Junctional adhesion molecule B & 5,6 & $4,1 \mathrm{E}-05$ & NO & YES \\
\hline 16 & GJB6 & Gap junction beta- 6 protein & 5,4 & $3,3 \mathrm{E}-05$ & NO & YES \\
\hline 17 & COX7A1 & Cytochrome c oxidase subunit 7A1, mitochondrial & 5,2 & $8,8 \mathrm{E}-05$ & NO & YES \\
\hline 18 & HHATL & $\begin{array}{l}\text { Protein-cysteine } \mathrm{N} \text {-palmitoyltransferase } \\
\text { protein }\end{array}$ & 5,2 & $9,3 \mathrm{E}-05$ & NO & YES \\
\hline 19 & CNR1 & Cannabinoid receptor 1 & 5,2 & $6,3 \mathrm{E}-05$ & NO & YES \\
\hline 20 & CD99 & CD99 antigen & 4,8 & $8,3 \mathrm{E}-06$ & NO & YES \\
\hline 21 & TMEM47 & $\begin{array}{l}\text { Transmembrane protein } 47 \text { (Brain cell membrane } \\
\text { protein 1) }\end{array}$ & 4,1 & $7,4 \mathrm{E}-07$ & NO & NO \\
\hline 22 & CPM & Carboxypeptidase M & 4,0 & $1,2 \mathrm{E}-04$ & NO & YES \\
\hline 23 & $A G T^{*}$ & Angiotensinogen (Serpin A8) & 3,9 & $6,7 \mathrm{E}-05$ & NO & YES \\
\hline 24 & NKAIN4 & $\begin{array}{l}\text { Sodium/potassium-transporting ATPase subunit beta-1- } \\
\text { interacting protein } 4\end{array}$ & 3,9 & $1,3 \mathrm{E}-04$ & NO & NO \\
\hline 25 & $A B C A 1$ & ATP-binding cassette sub-family A member 1 & 3,9 & $1,3 \mathrm{E}-05$ & NO & NO \\
\hline 26 & RGS5 & Regulator of G-protein signaling 5 & 3,8 & $2,2 \mathrm{E}-05$ & NO & NO \\
\hline 27 & S100B* & Protein S100-B & 3,7 & $1,1 \mathrm{E}-04$ & YES & YES \\
\hline 28 & FGF14 & Fibroblast growth factor 14 & 3,7 & $1,5 \mathrm{E}-04$ & NO & NO \\
\hline 29 & LHFP & LHFPL tetraspan subfamily member 6 protein & 3,6 & $4,8 \mathrm{E}-05$ & NO & NO \\
\hline 30 & TTYH1 & Protein tweety homolog 1 (hTTY1) & 3,5 & 4,9E-05 & NO & YES \\
\hline 31 & CST3* & Cystatin-C & 3,4 & $2,7 \mathrm{E}-06$ & YES & YES \\
\hline 32 & TEAD1 & Transcriptional enhancer factor-1 & 3,3 & 4,4E-05 & NO & NO \\
\hline 33 & MAOA* & Monoamine oxidase type A & 3,2 & $1,6 \mathrm{E}-05$ & YES & YES \\
\hline 34 & SLC1A2 & Excitatory amino acid transporter 2 & 3,2 & $7,6 \mathrm{E}-07$ & YES & YES \\
\hline 35 & PLEKHB1 & $\begin{array}{l}\text { Pleckstrin homology domain-containing family } B \\
\text { member } 1\end{array}$ & 3,1 & $5,3 \mathrm{E}-07$ & NO & YES \\
\hline 36 & GATM & Glycine amidinotransferase, mitochondrial & 2,8 & $6,7 \mathrm{E}-05$ & NO & YES \\
\hline 37 & CHN2 & Beta-chimaerin & 2,8 & $2,3 \mathrm{E}-05$ & NO & YES \\
\hline 38 & CADM1 & Cell adhesion molecule 1 & 2,6 & $1,9 \mathrm{E}-05$ & NO & YES \\
\hline 39 & PCSK2 & Neuroendocrine convertase 2 & 1,9 & $2,1 \mathrm{E}-05$ & NO & YES \\
\hline 40 & HSPH1 & Heat shock protein $105 \mathrm{kDa}$ & 1,7 & $1,3 \mathrm{E}-04$ & YES & YES \\
\hline 41 & SLC38A1 & Sodium-coupled neutral amino acid transporter 1 & 0,7 & $1,1 \mathrm{E}-04$ & NO & NO \\
\hline 42 & RABGAP1L & Rab GTPase-activating protein 1-like & 0,7 & $7,9 \mathrm{E}-05$ & NO & YES \\
\hline 43 & CCDC85A & Coiled-coil domain-containing protein $85 \mathrm{~A}$ & 0,6 & $1,5 \mathrm{E}-04$ & NO & YES \\
\hline 44 & MACROD2 & O-acetyl-ADP-ribose deacetylase MACROD2 & 0,6 & $1,0 \mathrm{E}-04$ & NO & YES \\
\hline 45 & LPGAT1 & Acyl-CoA:lysophosphatidylglycerol acyltransferase 1 & 0,6 & $1,1 \mathrm{E}-04$ & YES & YES \\
\hline 46 & KANK4 & $\begin{array}{l}\text { KN motif and ankyrin repeat domain-containing protein } \\
4\end{array}$ & 0,6 & $3,1 \mathrm{E}-05$ & NO & YES \\
\hline 47 & FAM126A & Hyccin & 0,5 & 3,3E-05 & NO & YES \\
\hline 48 & GSG1L & Germ cell-specific gene 1-like protein & 0,5 & $1,4 \mathrm{E}-04$ & NO & YES \\
\hline 49 & CBLN1* & Cerebellin-1 & 0,4 & $6,1 \mathrm{E}-05$ & YES & YES \\
\hline 50 & RGS16 & Regulator of G-protein signaling 16 & 0,4 & $6,6 \mathrm{E}-05$ & NO & NO \\
\hline 51 & RASGRF2 & Ras-specific guanine nucleotide-releasing factor 2 & 0,3 & $2,5 \mathrm{E}-05$ & NO & YES \\
\hline 52 & SSTR1 & Somatostatin receptor type 1 & 0,3 & $4,8 \mathrm{E}-05$ & NO & NO \\
\hline
\end{tabular}

Genes highlighted in gray were upregulated in our study. Genes highlighted in white were downregulated in our study. Genes marked with an asterisk (*) have been already reported as dysregulated in PD 
Table 3 Differentially expressed proteins between PD and control samples

\begin{tabular}{|c|c|c|c|c|}
\hline & Gene Name & Protein Description & $\begin{array}{l}\text { Fold Change } \\
\text { PD/CTRL }\end{array}$ & p-value \\
\hline 1 & VIM & Vimentin* & 3,5 & 0,017 \\
\hline 2 & CTSL & Cathepsin L1* & 3,0 & 0,033 \\
\hline 3 & GLIPR2 & Golgi-associated plant pathogenesis-related protein 1 & 2,3 & 0,007 \\
\hline 4 & ANXA2 & Annexin $\mathrm{A} 2^{*}$ & 2,2 & 0,004 \\
\hline 5 & $M B P$ & Myelin basic protein & 1,8 & 0,028 \\
\hline 6 & CST3 & Cystatin-C* & 1,8 & 0,018 \\
\hline 7 & $C P E$ & Carboxypeptidase E & 1,8 & 0,037 \\
\hline 8 & PMP2 & Myelin P2 protein & 1,7 & 0,035 \\
\hline 9 & CNP & 2,3-cyclic-nucleotide 3-phosphodiesterase & 1,6 & 0,050 \\
\hline 10 & UBA52;RPS27A;UBB;UBC & Ubiquitin-60S ribosomal protein $\mathrm{L} 40$ & 1,6 & 0,020 \\
\hline 11 & ASRGL1 & Isoaspartyl peptidase/L-asparaginase & 1,5 & 0,029 \\
\hline 12 & GJA1 & Gap junction alpha-1 protein & 1,5 & 0,032 \\
\hline 13 & PRKAR2B & cAMP-dependent protein kinase type II-beta regulatory subunit & 0,7 & 0,013 \\
\hline 14 & TIMM8A & Mitochondrial import inner membrane translocase subunit Tim8 A & 0,7 & 0,040 \\
\hline 15 & VARS & Valine--tRNA ligase & 0,6 & 0,038 \\
\hline 16 & STXBP5 & Syntaxin-binding protein 5 & 0,6 & 0,044 \\
\hline 17 & MARS & Methionine--tRNA ligase, cytoplasmic & 0,6 & 0,013 \\
\hline 18 & COPA & Coatomer subunit alpha & 0,6 & 0,033 \\
\hline 19 & SNRPD3 & Small nuclear ribonucleoprotein Sm D3 & 0,6 & 0,038 \\
\hline 20 & FKBP8 & Peptidyl-prolyl cis-trans isomerase FKBP8 & 0,6 & 0,039 \\
\hline 21 & CKAP4 & Cytoskeleton-associated protein 4 & 0,6 & 0,046 \\
\hline 22 & FXR2 & Fragile X mental retardation syndrome-related protein 2 & 0,5 & 0,048 \\
\hline 23 & $A P O O$ & Apolipoprotein O & 0,5 & 0,012 \\
\hline 24 & PDE10A & cAMP and cAMP-inhibited cGMP 3,5-cyclic phosphodiesterase $10 \mathrm{~A}$ & 0,5 & 0,043 \\
\hline 25 & NARS & Asparagine--tRNA ligase, cytoplasmic & 0,5 & 0,041 \\
\hline 26 & NOMO2;NOMO1;NOMO3 & Nodal modulator 2 & 0,5 & 0,009 \\
\hline 27 & GBE1 & 1,4-alpha-glucan-branching enzyme & 0,5 & 0,012 \\
\hline 28 & DNAJB11 & DnaJ homolog subfamily B member 11 & 0,5 & 0,020 \\
\hline 29 & FABP7 & Fatty acid-binding protein, brain & 0,4 & 0,028 \\
\hline 30 & CDS2 & Phosphatidate cytidylyltransferase 2 & 0,4 & 0,034 \\
\hline 31 & $A L D H 1 A 1$ & Aldehyde dehydrogenase $1^{*}$ & 0,4 & 0,024 \\
\hline 32 & FKBP4 & Peptidyl-prolyl cis-trans isomerase FKBP4 & 0,4 & 0,046 \\
\hline 33 & SERPINA1 & Alpha-1-antitrypsin* & 0,3 & 0,043 \\
\hline
\end{tabular}

Proteins highlighted in gray were upregulated in our study. Proteins highlighted in white were downregulated in our study. Proteins marked with an asterisk (*) have been already described in PD as dysregulated

genes are of particular interest: the upregulation of $M T 1 H$, CXCR4, PNMT, BTG3, LRP2, AGT, SIOOB, MAOA and $C S T 3$ and the downregulation of $C B L N 1$ have been observed in previous studies investigating PD or other neurological disorders. Upregulated genes showed differences ranging from 3-fold change for $M A O A$ to 98 -fold change for $M T 1 H$, while $C B L N 1$ was downregulated with a 2.5 -fold change.

Second, we compared protein expression between PD and control groups using label-free quantification (LFQ). Among the 1034 identified proteins, 33 (3.2\%) were differentially expressed ( $t$-test, $p$ value $<0.05)$ between PD and control, with at least a 1.5 -fold change (Table 3 ), including 12 proteins with increased and 21 with decreased expression in PD samples. Among these 33 differentially expressed proteins, three upregulated, cystatin-C, cathepsin L1, Annexin A2, and two downregulated, Aldehyde dehydrogenase 1 and alpha-1-antitrypsin, proteins in PD samples deserve a particular attention as they also appeared dysregulated in previous publications involving PD or other neurological disorders. PD-overexpressed proteins showed differences ranging from 1.8-fold change for cystatin-C to 3.5-fold change for vimentin, while downregulated proteins showed differences ranging from 2.5 -fold change for aldehyde dehydrogenase 1 to 3.7-fold change for alpha-1-antitrypsin.

Somewhat surprisingly, correlation of transcriptomic and proteomic analyses only revealed one common event: the CST-3 gene and its corresponding translated protein cystatin$\mathrm{C}$ that were both significantly upregulated in PD samples. That was not the case for $S 100 \mathrm{~B}$ and MAOA, 2 upregulated genes in our study, as expression of their corresponding protein was not significantly different in PD samples. Concerning the six others interesting genes (MT1H, CXCR4, PNMT, $B T G 3, L R P 2, A G T)$, their corresponding proteins were not identified by our proteomic workflow. To better understand the low correlation between transcriptomic and proteomic data, we focused on the proteins identified and quantified in our proteomic workflow and present in the list of the 52 differentially expressed genes. In fact, only 7 gene-related proteins (13.5\%) were identified by nano-LC-MS/MS among the potential 52 gene products, whereas no corresponding 
protein for the 45 remaining dysregulated genes could be found, making correlation between transcriptomic and proteomic data impossible. Among these 52 genes, 19 had never seen their corresponding protein identified by MS from brain samples according to Nextprot database (Table 2).

In summary, this second part of the study was devoted to compare for the first time RNA and protein expressions from DA neurons, in PD and control SNpc. These comparative analyses separately revealed relevant differences of expression in PD samples, supporting previous observations conducted in whole SNpc studies. However, correlation between transcriptomic and proteomic data was limited by our proteomic workflow. In fact, while the transcriptomic approach provided information about approximately 15,000 genes, the proteomic approach was limited to 1000 proteins. Moreover, the proteins corresponding to the majority of dysregulated genes were not identified by our nano-LC-MS/MS-related workflow.

\section{Discussion}

The difficulty to identify key molecular mechanisms at the basis of PD is a major obstacle to the development of neuroprotective therapies. DA neurons in the $\mathrm{SN} p c$ represent the main cellular compartment affected by degeneration in PD and thus appear as relevant entities to isolate and analyze.

In this study, we used LCM to extract DA neuronal regions from post-mortem control and PD SNpc. RNA-based analysis confirmed sufficient quality of all used samples for molecular analyses. A qualitative proteomic analysis of our samples showed high similarity with Plum et al. (2016) who, using LCM-coupled nano-LC-MS/MS, provided an exhaustive proteome of DA neurons from healthy subjects. Our present study confirms the feasibility and the relevance of such workflow and updates the human proteome of DA neurons with new identified proteins. Moreover, the comparison of our list with the whole SN $p c$ proteome published by our group (Licker et al. 2014) confirmed that using LCM allows access to a specific subproteome, here composed of 170 species, which were not identified in the whole $\mathrm{SN} p c$ samples despite a protein fractionation protocol. These 170 proteins also update the human proteome of the SNpc.

We then applied both quantitative proteomic and transcriptomic workflows to our dissected DA neuronal regions in order to identify specific molecular events in PD-related samples. To our knowledge, we are the first (1) to compare protein expression of DA neuronal regions in PD and control samples and (2) to apply both proteomic and transcriptomic workflows from these samples. The real challenge to perform this kind of comparative analysis relies on the high number of tissue sections required for PD samples. In fact, for each PD sample, an average of 37 tissue sections were microdissected in order to collect enough DA neuronal regions. In total, more than 300 tissue sections were required for this multiomic study. This information reflects the significant DA-neuron loss observed in PD samples and thus the highly challenging context to perform these experiments.

In our study, the comparative analysis of gene expression revealed 52 dysregulated entities in PD samples, among which $L R P 2$ was upregulated. $L R P 2$ encodes for megalin receptor, also known as the neuronal receptor for metallothionein proteins, proteins whose function as metal exchanger would be neuroprotective for brain tissue. In PD context, gene expression of $L R P 2$ has been previously reported to increase in nigral DA neurons (Michael et al. 2011).

$P N M T$ encoding for phenylethanolamine $N$-methyltransferase was also upregulated in our study. Interestingly, phenylethanolamine $N$-methyltransferase can induce, through its catalytic activity, cytotoxic $\mathrm{N}$-methylated beta carbolineum cations, which have structural and functional similarity with neurotoxic 1-methyl-4-phenyl-pyridinium cation (MPP+). Several studies have shown that within DA neurons, PNMTinduced beta carbolineum cations inhibit mitochondrial respiration (Drucker et al. 1990; Matsubara et al. 1998). High PNMT catalytic activity has been observed in SNpc and locus coeruleus, the two most affected brain areas in PD (Kopp et al. 1979). Thus, our results confirm previous observations and strengthen the hypothesis suggesting that increased levels of PNMT could induce neurotoxin-mediated death (Gearhart et al. 2002).

In PD brain, increased activation of microglia releases pro-inflammatory molecules such as cytokines and may contribute to neuronal damage observed in this disorder. Among cytokines, CXCR4 and its ligand CXCL12 are important members of the chemokine family and are expressed in the central nervous system. In 2009, Shimoji et al. demonstrated that CXCR4 was elevated in SNpc DA neurons, more in PD than in control samples (Shimoji et al. 2009). In the same study, the authors also suggested that increased CXCR4 expression occurs before and is not consecutive to DA neuronal loss. Thus, CXCR4 signaling would enhance the loss of DA neurons. In our study, we observed the upregulation of CXCR4 gene expression in PD samples, confirming results from previous studies and the important role of inflammation in PD degeneration.

The enzyme monoamine oxidase A (MAOA) is a drug target in the treatment of PD (Miklya 2016). The inhibition of MAO by drugs prevents dopamine breakdown, maintaining a higher level of dopamine into the brain of PD patients. MAOA is principally located in neurons and is primarily responsible for dopamine metabolism in the latter (Levitt et al. 1982). In 2017, Tong et al. observed a $33 \%$ increase of the protein expression of MAOA in PD-related whole $\mathrm{SN} p c$ (Tong et al. 2017). Considering that MAOA is mainly 
expressed in dopamine neurons, which are reduced in PD conditions, they were surprised by these observations and proposed different explanations including the expression of MAOA by glial cells or an upregulation of MAOA into surviving DA neurons.

In our present study, we observed an increased expression of $M A O A$ gene in PD DA neurons supporting an upregulation of MAOA into surviving DA neurons, although we cannot entirely exclude contamination by others cells. These results confirm previous observations and strengthen the interest toward MAO inhibitors for symptomatic purposes.

In our study, we observed a downregulation of CBLN1, that encodes for cerebellin 1 protein, in PD samples. In 2018, Zucca et al. confirmed the expression of cerebellin-1 protein into DA neurons (Zucca et al. 2018).

CBLN1 is among the most consistently reported downregulated genes across studies on PD (Grunblatt et al. 2004; Moran et al. 2006). Cerebellins are hexameric protein hormones with neuromodulator functions. Their physiological role is not entirely elucidated although it has been reported that cerebellins increase norepinephrine synthesis. Consequently, when not enough cerebellin is present in the brain, the level of dopamine might also decrease.

All these dysregulated genes have been previously described in others studies and are particularly interesting according to the function of the corresponding proteins. Unfortunately, the quantitative expression of these corresponding proteins could not be measured in our samples. In fact, while RNAseq provides a complete picture of all expressed transcripts and because low copy mRNAs are also amplified during the workflow, protein identification using non-targeted MS-related proteomics is limited by instrument-related dynamic range. Indeed, for 19 out of the 52 dysregulated genes, the protein product has never been identified by MS approaches. Moreover, among the 1034 identified and quantified proteins, only 7 were encoded by genes we observed as dysregulated in our study. At first glance, the low correlation between transcriptomic and proteomic data may seem odd but several previous studies have already confirmed this trend (Greenbaum et al. 2003). For example, in 2016, Dumitriu et al. (2016) compared RNA and protein expression from post-mortem human prefrontal cortex in PD and control samples. Although 283 proteins and 1095 mRNAs were significantly different between PD and controls, only 8 genes were in common and with the same direction effect between the two sets of results. Greenbaum et al. (2003) propose at least three main reasons to explain poor correlation between mRNA and protein levels, including the multiple, complex and varied post-transcriptional mechanisms involved in turning mRNA into protein, the difference in in vivo half-lives between RNA and protein, and the significant amount of error and noise in both protein and mRNA experiments.
Nevertheless, despite this poor correlation, our proteomic analysis also revealed dysregulated proteins of interest in PD samples. Indeed, in our study, the expression of cystatin C protein was increased in PD samples and followed the same direction of expression as its gene, CST3. Cystatin $\mathrm{C}$ is an endogenous inhibitor of cysteine proteases such as cathepsins $\mathrm{B}, \mathrm{H}, \mathrm{K}, \mathrm{S}$, and $\mathrm{L}$ and is present in all mammalian body fluid and tissues (Bobek and Levine 1992). Increased expression of cystatin $\mathrm{C}$ in cerebrospinal fluid has been highlighted in many neurodegenerative disorders, including Alzheimer's disease, and it was suggested to be of diagnostic interest (Deng et al. 2001; Yamamoto-Watanabe et al. 2010). In PD, Xu et al. (2005) demonstrated an overexpression of the CST3 gene and higher levels of cystatin $\mathrm{C}$ in DA-depleted rat striatum. In the same line, we here describe for the first time an increased cystatin gene and protein expressions in human DA neurons of PD patients.

Recent in vitro (Kumada et al. 2004; Hasegawa et al. 2007; Tizon et al. 2010) and in vivo (Xu et al. 2005; Kaur et al. 2010) results have suggested a neuroprotective role of cystatin C. In fact, administration of human cystatin C into the rat $\mathrm{SN} p c$ partially rescued DA neurons following a 6-OHDA-induced lesion. This neuroprotective function of cystatin $\mathrm{C}$ may be related to its inhibitory action on cathepsins and/or to induction of autophagy.

We also observed an increased expression of cathepsin L1 in PD samples. Cathepsin L is a lysosomal cysteine endopeptidase and many in vivo studies associated cathepsins $\mathrm{L}$ in the maintenance of the central nervous system (Felbor et al. 2002). Cathepsins that are typically localized in lysosomes, endosomes, or vesicles could be released into the cytoplasm of degenerating neurons (Roberg and Ollinger 1998) and generate an imbalance between cystatin C (inhibitor of proteases) and cathepsins (cysteine proteases), which has been associated to Alzheimer's disease (Nakamura et al. 1991). In 2010, Li et al. (2011) observed an abnormal cytoplasmic distribution and an increased expression of cathepsin L in DA neurons of PD patients. They also showed that inhibition of cathepsin L partially protected DA neurons from cell death induced by 6-OHDA in rodent models. Both cystatin C (Tizon et al. 2010) and cathepsins (Man and Kanneganti 2016) are involved in autophagy. Autophagy usually occurs in normal cells to preserve neuronal health by maintaining cellular turnover, clearance, and regeneration of new components. Autophagy is greatly increased in pathological contexts such as nutritional deprivation (Young et al. 2009), oxidative stress (Ciccarone et al. 2019), or hypoxia (Bellot et al. 2009). In addition, an excessive or imbalanced induction of the autophagy pathway may induce a caspaseindependent form of cell death that shares many features with apoptosis (Bursch 2001; Borsello et al. 2003). According to our results, one hypothesis we may venture into is that the abnormal presence of cathepsin L into degenerating DA 
neurons of PD patients would induce increased expression of cystatin $\mathrm{C}$, which would overactivate the autophagy pathway leading to neuronal death.

In our study, we also observed a decreased expression of Aldehyde dehydrogenase 1 in PD samples.

Encoded by ALDHIA gene, Aldehyde dehydrogenase 1 is a detoxification enzyme that participates in the metabolism of both dopamine (DA) and norepinephrine. It is exclusively expressed in DA neurons where it converts by oxidation a toxic metabolite of dopamine, the 3,4 dihydroxyphenylacetaldehyde (DOPAL) into a non-toxic form, the dihydrophenylacetic acid (DOPAC). In 2003, Galter et al. (2003) observed a decreased expression of ALDHIA mRNA in DA neurons of SNpc from PD patients, while DA neurons of VTA from the same patients were unaffected. Here, our study reveals for the first time a decreased expression of its gene product Aldehyde dehydrogenase 1 . We could interpret this finding in two different ways. First, decreased expression of Aldehyde dehydrogenase 1 in SNpc DA neurons of PD patients might be a consequence of PD-related degenerative process and thus a compensatory mechanism to slow down the rate of DA-neuron degradation. Alternatively, this decreased expression of Aldehyde dehydrogenase 1 could also contribute to PD-related degeneration by allowing accumulation of DOPAL and aldehyde toxicity in DA neurons. Further studies are still necessary to appreciate whether decreased expression of Aldehyde dehydrogenase 1 may be involved in the development or the perpetuation of PD pathomechanisms.

\section{Conclusion}

This descriptive and exploratory study is the first to generate proteomic (SI-1) and transcriptomic data (SI-2) from DA neuronal regions in PD SNpc and results reported above underline the potential interest of such combined molecular approaches. However, this study has also limitations, including a small set of samples and all expression changes reported above should be confirmed in more PD samples and with orthogonal approaches. Furthermore, although remaining the gold standard to decipher brain molecular alterations, autopsied tissues are associated with several drawbacks including difficulty to collect them and risks of degradation and contamination by agonal or post-mortem changes $(\mathrm{Li}$ et al. 2004; Crecelius et al. 2008). In fact, a massive and spreading depolarization of neurons with a high release of glutamate and potassium has been described shortly before brain death (Carlson et al. 2018). This phenomenon probably changes molecular expression in neurons, independently of PD-related events. Moreover, the post-mortem interval has also an impact on RNA and protein expression. Therefore, it may seem that the ultimate sample for research in human PD has to be safely obtained from a large number of living individuals, and sampling-to-freezer time should be kept as short as possible. Brain tissue imprints that can be collected during deep brain stimulation surgery appear promising samples for future studies using RNA sequencing or proteomics (Zaccaria et al. 2016).

Supplementary Information The online version contains supplementary material available at https://doi.org/10.1007/s10571-021-01146-8.

Acknowledgements We thank the Histology, Bioimaging, Genomic, and Proteomic Core Facilities for their technical support and willingness to help. Our gratitude goes also to Michele El Atifi for her suggestions on the matter of the RNA analysis.

Author Contributions AZ, VL, and PRB designed the study. VL and PA performed the experiment. JAL and EK collected human specimens and confirmed the neuropathological diagnostic. AZ and PA analyzed the data. AZ, PA, and PRB drafted the manuscript. All the authors have seen and approved the final version of the manuscript.

Funding Open Access funding provided by Université de Genève. This work was supported by the Swiss National Science Foundation 31003A_143987 and Parkinson Swiss.

Data Availability All data relevant to the study are included in the article or as Supplementary Information. Upon reasonable request, additional information will be shared by the corresponding authors.

\section{Declarations}

Conflict of interest The authors declare that they have no competing interests.

Ethical Approval Midbrain tissues were obtained from the Division of Clinical Pathology and Psychiatry of the Geneva University Hospitals under a procedure approved by the Local Ethical Committee.

Informed Consent Written consents for brain autopsy and use for research purpose were signed by close relatives.

Consent for Publication All authors of the manuscript have read and agreed to its content.

Open Access This article is licensed under a Creative Commons Attribution 4.0 International License, which permits use, sharing, adaptation, distribution and reproduction in any medium or format, as long as you give appropriate credit to the original author(s) and the source, provide a link to the Creative Commons licence, and indicate if changes were made. The images or other third party material in this article are included in the article's Creative Commons licence, unless indicated otherwise in a credit line to the material. If material is not included in the article's Creative Commons licence and your intended use is not permitted by statutory regulation or exceeds the permitted use, you will need to obtain permission directly from the copyright holder. To view a copy of this licence, visit http://creativecommons.org/licenses/by/4.0/.

\section{References}

Bellot G, Garcia-Medina R, Gounon P, Chiche J, Roux D, Pouyssegur J, Mazure NM (2009) Hypoxia-induced autophagy is mediated 
through hypoxia-inducible factor induction of BNIP3 and BNIP3L via their BH3 domains. Mol Cell Biol 29(10):2570-2581

Berg D, Gerlach M, Youdim MB, Double KL, Zecca L, Riederer P, Becker G (2001) Brain iron pathways and their relevance to Parkinson's disease. J Neurochem 79(2):225-236

Bobek LA, Levine MJ (1992) Cystatins-inhibitors of cysteine proteinases. Crit Rev Oral Biol Med 3(4):307-332

Borsello T, Croquelois K, Hornung JP, Clarke PG (2003) N-methyl$\mathrm{D}$-aspartate-triggered neuronal death in organotypic hippocampal cultures is endocytic, autophagic and mediated by the c-Jun N-terminal kinase pathway. Eur J Neurosci 18(3):473-485

Bursch W (2001) The autophagosomal-lysosomal compartment in programmed cell death. Cell Death Differ 8(6):569-581

Carlson AP, Abbas M, Alunday RL, Qeadan F, Shuttleworth CW (2018) Spreading depolarization in acute brain injury inhibited by ketamine: a prospective, randomized, multiple crossover trial. J Neurosurg. https://doi.org/10.3171/2017.12.jns171665

Ciccarone F, Castelli S, Ciriolo MR (2019) Oxidative stress-driven autophagy acROSs onset and therapeutic outcome in hepatocellular carcinoma. Oxid Med Cell Longev 2019:6050123

Crecelius A, Gotz A, Arzberger T, Frohlich T, Arnold GJ, Ferrer I, Kretzschmar HA (2008) Assessing quantitative post-mortem changes in the gray matter of the human frontal cortex proteome by 2-D DIGE. Proteomics 8(6):1276-1291

Deng A, Irizarry MC, Nitsch RM, Growdon JH, Rebeck GW (2001) Elevation of cystatin $\mathrm{C}$ in susceptible neurons in Alzheimer's disease. Am J Pathol 159(3):1061-1068

Dor M, Eperon S, Lalive PH, Guex-Crosier Y, Hamedani M, Salvisberg C, Turck N (2019) Investigation of the global protein content from healthy human tears. Exp Eye Res 179:64-74

Drucker G, Raikoff K, Neafsey EJ, Collins MA (1990) Dopamine uptake inhibitory capacities of beta-carboline and 3,4-dihydro-beta-carboline analogs of $N$-methyl-4-phenyl-1,2,3,6tetrahydropyridine (MPTP) oxidation products. Brain Res 509(1):125-133

Dumitriu A, Golji J, Labadorf AT, Gao B, Beach TG, Myers RH, Longo KA, Latourelle JC (2016) Integrative analyses of proteomics and RNA transcriptomics implicate mitochondrial processes, protein folding pathways and GWAS loci in Parkinson disease. BMC Med Genomics 9:5

Espina V, Heiby M, Pierobon M, Liotta LA (2007) Laser capture microdissection technology. Expert Rev Mol Diagn 7(5):647-657

Felbor U, Kessler B, Mothes W, Goebel HH, Ploegh HL, Bronson RT, Olsen BR (2002) Neuronal loss and brain atrophy in mice lacking cathepsins B and L. Proc Natl Acad Sci USA 99(12):7883-7888

Galter D, Buervenich S, Carmine A, Anvret M, Olson L (2003) ALDH1 mRNA: presence in human dopamine neurons and decreases in substantia nigra in Parkinson's disease and in the ventral tegmental area in schizophrenia. Neurobiol Dis 14(3):637-647

Gaudet P, Michel PA, Zahn-Zabal M, Britan A, Cusin I, Domagalski M, Duek PD, Gateau A, Gleizes A, Hinard V, Rech de Laval V, Lin J, Nikitin F, Schaeffer M, Teixeira D, Lane L, Bairoch A (2017) The neXtProt knowledgebase on human proteins: 2017 update. Nucleic Acids Res 45(D1):D177-D182

Gearhart DA, Neafsey EJ, Collins MA (2002) Phenylethanolamine $\mathrm{N}$-methyltransferase has beta-carboline $2 \mathrm{~N}$-methyltransferase activity: hypothetical relevance to Parkinson's disease. Neurochem Int 40(7):611-620

Greenbaum D, Colangelo C, Williams K, Gerstein M (2003) Comparing protein abundance and mRNA expression levels on a genomic scale. Genome Biol 4(9):117

Grunblatt E, Mandel S, Jacob-Hirsch J, Zeligson S, Amariglo N, Rechavi G, Li J, Ravid R, Roggendorf W, Riederer P, Youdim MB (2004) Gene expression profiling of Parkinsonian substantia nigra pars compacta; alterations in ubiquitin-proteasome, heat shock protein, iron and oxidative stress regulated proteins, cell adhesion/cellular matrix and vesicle trafficking genes. J Neural Transm (Vienna) 111(12):1543-1573

Hasegawa A, Naruse M, Hitoshi S, Iwasaki Y, Takebayashi H, Ikenaka K (2007) Regulation of glial development by cystatin C. J Neurochem 100(1):12-22

Jenner P (2003) Oxidative stress in Parkinson's disease. Ann Neurol 53(Suppl 3):S26-S36; discussion S28-S36

Kalia LV, Lang AE (2015) Parkinson's disease. Lancet 386(9996):896-912

Kaur G, Mohan P, Pawlik M, DeRosa S, Fajiculay J, Che S, Grubb A, Ginsberg SD, Nixon RA, Levy E (2010) Cystatin C rescues degenerating neurons in a cystatin B-knockout mouse model of progressive myoclonus epilepsy. Am J Pathol 177(5):2256-2267

Kopp N, Denoroy L, Renaud B, Pujol JF, Tabib A, Tommasi M (1979) Distribution of adrenaline-synthesizing enzyme activity in the human brain. J Neurol Sci 41(3):397-409

Kumada T, Hasegawa A, Iwasaki Y, Baba H, Ikenaka K (2004) Isolation of cystatin $\mathrm{C}$ via functional cloning of astrocyte differentiation factors. Dev Neurosci 26(1):68-76

Levitt P, Pintar JE, Breakefield XO (1982) Immunocytochemical demonstration of monoamine oxidase $\mathrm{B}$ in brain astrocytes and serotonergic neurons. Proc Natl Acad Sci USA 79(20):6385-6389

Li JZ, Vawter MP, Walsh DM, Tomita H, Evans SJ, Choudary PV, Lopez JF, Avelar A, Shokoohi V, Chung T, Mesarwi O, Jones EG, Watson SJ, Akil H, Bunney WE Jr, Myers RM (2004) Systematic changes in gene expression in postmortem human brains associated with tissue $\mathrm{pH}$ and terminal medical conditions. Hum Mol Genet 13(6):609-616

Li L, Wang X, Fei X, Xia L, Qin Z, Liang Z (2011) Parkinson's disease involves autophagy and abnormal distribution of cathepsin L. Neurosci Lett 489(1):62-67

Licker V, Turck N, Kovari E, Burkhardt K, Cote M, Surini-Demiri M, Lobrinus JA, Sanchez JC, Burkhard PR (2014) Proteomic analysis of human substantia nigra identifies novel candidates involved in Parkinson's disease pathogenesis. Proteomics 14(6):784-794

Man SM, Kanneganti TD (2016) Regulation of lysosomal dynamics and autophagy by CTSB/cathepsin B. Autophagy 12(12):2504-2505

Matsubara K, Gonda T, Sawada H, Uezono T, Kobayashi Y, Kawamura T, Ohtaki K, Kimura K, Akaike A (1998) Endogenously occurring beta-carboline induces Parkinsonism in nonprimate animals: a possible causative protoxin in idiopathic Parkinson's disease. J Neurochem 70(2):727-735

McGeer PL, McGeer EG (2004) Inflammation and neurodegeneration in Parkinson's disease. Parkinsonism Relat Disord 10(Suppl 1):S3-7

McNaught KS, Olanow CW, Halliwell B, Isacson O, Jenner P (2001) Failure of the ubiquitin-proteasome system in Parkinson's disease. Nat Rev Neurosci 2(8):589-594

Michael GJ, Esmailzadeh S, Moran LB, Christian L, Pearce RK, Graeber MB (2011) Up-regulation of metallothionein gene expression in Parkinsonian astrocytes. Neurogenetics 12(4):295-305

Miklya I (2016) The significance of selegiline/(-)-deprenyl after 50 years in research and therapy (1965-2015). Mol Psychiatry 21(11):1499-1503

Moran LB, Duke DC, Deprez M, Dexter DT, Pearce RK, Graeber MB (2006) Whole genome expression profiling of the medial and lateral substantia nigra in Parkinson's disease. Neurogenetics $7(1): 1-11$

Nakamura Y, Takeda M, Suzuki H, Hattori H, Tada K, Hariguchi S, Hashimoto S, Nishimura T (1991) Abnormal distribution of cathepsins in the brain of patients with Alzheimer's disease. Neurosci Lett 130(2):195-198

Perez-Riverol Y, Csordas A, Bai J, Bernal-Llinares M, Hewapathirana S, Kundu DJ, Inuganti A, Griss J, Mayer G, Eisenacher M, Perez E, Uszkoreit J, Pfeuffer J, Sachsenberg T, Yilmaz S, Tiwary S, Cox J, Audain E, Walzer M, Jarnuczak AF, Ternent T, Brazma 
A, Vizcaino JA (2019) The PRIDE database and related tools and resources in 2019: improving support for quantification data. Nucleic Acids Res 47(D1):D442-D450

Plum S, Steinbach S, Attems J, Keers S, Riederer P, Gerlach M, May C, Marcus K (2016) Proteomic characterization of neuromelanin granules isolated from human substantia nigra by laser-microdissection. Sci Rep 6:37139

Redensek S, Dolzan V, Kunej T (2018) From genomics to omics landscapes of Parkinson's disease: revealing the molecular mechanisms. OMICS 22(1):1-16

Roberg K, Ollinger K (1998) Oxidative stress causes relocation of the lysosomal enzyme cathepsin $\mathrm{D}$ with ensuing apoptosis in neonatal rat cardiomyocytes. Am J Pathol 152(5):1151-1156

Scherl A, Shaffer SA, Taylor GK, Kulasekara HD, Miller SI, Goodlett DR (2008) Genome-specific gas-phase fractionation strategy for improved shotgun proteomic profiling of proteotypic peptides. Anal Chem 80(4):1182-1191

Shimoji M, Pagan F, Healton EB, Mocchetti I (2009) CXCR4 and CXCL12 expression is increased in the nigro-striatal system of Parkinson's disease. Neurotox Res 16(3):318-328

Simunovic F, Yi M, Wang Y, Macey L, Brown LT, Krichevsky AM, Andersen SL, Stephens RM, Benes FM, Sonntag KC (2009) Gene expression profiling of substantia nigra dopamine neurons: further insights into Parkinson's disease pathology. Brain 132(Pt 7):1795-1809

Tizon B, Sahoo S, Yu H, Gauthier S, Kumar AR, Mohan P, Figliola M, Pawlik M, Grubb A, Uchiyama Y, Bandyopadhyay U, Cuervo AM, Nixon RA, Levy E (2010) Induction of autophagy by cystatin $C$ : a mechanism that protects murine primary cortical neurons and neuronal cell lines. PLoS ONE 5(3):e9819

Tong J, Rathitharan G, Meyer JH, Furukawa Y, Ang LC, Boileau I, Guttman M, Hornykiewicz O, Kish SJ (2017) Brain monoamine oxidase $\mathrm{B}$ and $\mathrm{A}$ in human Parkinsonian dopamine deficiency disorders. Brain 140(9):2460-2474
Vono M, Eberhardt CS, Auderset F, Mastelic-Gavillet B, Lemeille S, Christensen D, Andersen P, Lambert PH, Siegrist CA (2019) Maternal antibodies inhibit neonatal and infant responses to vaccination by shaping the early-life B cell repertoire within germinal centers. Cell Rep 28(7):1773-1784.e1775

Xu L, Sheng J, Tang Z, Wu X, Yu Y, Guo H, Shen Y, Zhou C, Paraoan L, Zhou J (2005) Cystatin C prevents degeneration of rat nigral dopaminergic neurons: in vitro and in vivo studies. Neurobiol Dis 18(1):152-165

Yamamoto-Watanabe Y, Watanabe M, Jackson M, Akimoto H, Sugimoto K, Yasujima M, Wakasaya Y, Matsubara E, Kawarabayashi T, Harigaya Y, Lyndon AR, Shoji M (2010) Quantification of cystatin $\mathrm{C}$ in cerebrospinal fluid from various neurological disorders and correlation with G73A polymorphism in CST3. Brain Res 1361:140-145

Young JE, Martinez RA, La Spada AR (2009) Nutrient deprivation induces neuronal autophagy and implicates reduced insulin signaling in neuroprotective autophagy activation. J Biol Chem 284(4):2363-2373

Zaccaria A, Bouamrani A, Chabardes S, El Atifi M, Seigneuret E, Lobrinus JA, Dubois-Dauphin M, Berger F, Burkhard PR (2016) Deep brain stimulation-associated brain tissue imprints: a new in vivo approach to biological research in human Parkinson's disease. Mol Neurodegener 11:12

Zucca FA, Vanna R, Cupaioli FA, Bellei C, De Palma A, Di Silvestre D, Mauri P, Grassi S, Prinetti A, Casella L, Sulzer D, Zecca L (2018) Neuromelanin organelles are specialized autolysosomes that accumulate undegraded proteins and lipids in aging human brain and are likely involved in Parkinson's disease. NPJ Parkinsons Dis 4:17

Publisher's Note Springer Nature remains neutral with regard to jurisdictional claims in published maps and institutional affiliations. 